\title{
Democratic Representation and Partisan Bias in Congressional Elections
}

\section{Citation}

King, Gary, and Robert X. Browning. 1987. Democratic representation and partisan bias in congressional elections. American Political Science Review 81(4): 1251-1273.

\section{Published Version}

doi: $10.2307 / 1962588$

\section{Permanent link}

http://nrs.harvard.edu/urn-3:HUL.InstRepos:4455010

\section{Terms of Use}

This article was downloaded from Harvard University's DASH repository, and is made available under the terms and conditions applicable to Other Posted Material, as set forth at http:// nrs.harvard.edu/urn-3:HUL.InstRepos:dash.current.terms-of-use\#LAA

\section{Share Your Story}

The Harvard community has made this article openly available.

Please share how this access benefits you. Submit a story.

Accessibility 


\section{DEMOCRATIC REPRESENTATION AND PARTISAN BIAS IN CONGRESSIONAL ELECTIONS

\author{
GARY KING \\ Harvard University \\ ROBERT X BROWNING \\ Purdue University
}

$T_{h e}$

he translation of citizen votes into legislative seats is of central importance in democratic electoral systems. It has been a longstanding concern among scholars in political science and in numerous other disciplines. Throughout this literature, two fundamental tenets of democratic theory, partisan bias and democratic representation, have often been confused. We develop a general statistical model of the relationship between votes and seats and separate these two important concepts theoretically and empirically. In so doing, we also solve several methodological problems with the study of seats, votes, and the cube law. An application to U.S. congressional districts provides estimates of bias and representation for each state and demonstrates the model's utility. Results of this application show distinct types of representation coexisting in U.S. states. Although most states have small partisan biases, there are some with a substantial degree of bias.

$T_{1}$ he relationship between legislative seats and citizen votes is a longstanding concern in democratic theory (e.g., Balinski and Young 1982; Dahl 1956, 147-49; Farrand 1911; Locke 1965, 419-20; Rae 1967; Schattschneider 1942). Through this relationship, legislative majorities are formed and minorities protected. Constitutionally mandated reapportionment and shifting patterns of partisanship have created opportunities for state legislatures and partisan gerrymanders to alter the congressional seatsvotes relationship (Cain 1984; Grofman et al. 1982; Polsby 1971). Over the last century, scholars in political science, sociology, economics, mathematics, statistics, and political geography have studied these normative theoretical questions and sought empirical estimates of bias and unfairness (Hay and Rumley 1984; Ken- dall and Stuart 1950; March 1957-58; Theil 1970; Tufte 1973). Furthermore, the recent spate of court challenges, the courts' willingness to hear political gerrymandering cases, and the Supreme Court's interest in a threshold of political discrimination, have rekindled the seatsvotes controversy (Karcher v. Daggett, 462 U.S. 725 [1983]; Davis v. Bandemer, 478 U.S. [1986]; Brown v. Thomson, 462 U.S. 835 [1983]).

Concern with and, we believe, confusion over two fundamental tenets of democratic theory, partisan bias and democratic representation, dominate this literature. Partisan bias introduces asymmetry into the seats-votes relationship, resulting in an unfair partisan differential in the ability to win legislative seats: the advantaged party will be able to receive a larger number of seats for a fixed number 


\section{American Political Science Review Vol. 81}

of votes than will the disadvantaged party. Although bias is easily defined, it is not always as apparent or as easily measured (Grofman 1983). Even in the absence of partisan bias, several forms of democratic representation are possible: strict proportional representation-in which the percentage of seats equals the percentage of votes-and winner-take-all elections are the pure forms, with many other possibilities in between. ${ }^{1}$ Whereas the extent of bias is a separate problem, the precise effect of partisan bias depends on the specific form of democratic representation.

Much of the literature either treats partisan bias and democratic representation as one concept or mistakenly confuses different democratically legitimate forms of representation with clearly invidious partisan bias. Because bias and representation are related, the separate estimations in most previous research can be shown to be statistically inconsistent. By expressing each of these concepts as a separate parameter in a unified model, we show that it is possible and useful to emphasize the analytical and empirical distinctions by developing a model that jointly estimates both of these parameters. In a single and conceptually simple equation, we incorporate the full range of possible values for bias and representation. The result is a general form that is useful in understanding both the fairness of legislative reapportionment and the democratic character of legislative representation. The validity and utility of this model is then demonstrated with an application to state level congressional seats and votes for the period 1950-84.

The essence of bias and representation in democratic regimes is realized in the translation of votes into seats. ${ }^{2}$ Assume initially that there are only two parties, Democratic and Republican, and that the legislature is composed of a set of singlemember, winner-take-all districts. We begin with a few standard definitions. Let $v=$ the number of votes cast for Democratic party candidates

$T=$ the total number of votes cast for candidates of both parties

$v_{R}=T-v=$ the number of votes cast for Republican party candidates

$V=v / T=$ the proportion of votes cast for Democratic candidates

$V_{R}=1-V=$ the proportion of votes cast for Republican candidates

$s=$ the number of seats allocated to the Democratic party candidates

$s_{R}=$ the number of seats allocated to the Republican party candidates

$D=$ the total number of singlemember legislative districts

$S=s / D=$ the proportion of seats allocated to the Democratic candidates

$S_{R}=1-S=$ the proportion of seats allocated to the Republican candidates

We express the absence of partisan bias as partisan symmetry. In general, this means that in an election system where $x \%$ of the Democratic votes produces an allocation of $y \%$ of the seats to the Democrats, then in another election under the same system $x \%$ of the Republican votes would yield the same $y \%$ Republican allocation of seats. This is the situation that Grofman (1983) calls "completely unbiased."

Stated more formally, if $V=x \Rightarrow S=$ $y$, then $V_{R}=x \Rightarrow S_{R}=y$, for all $x$ and $y$. This completely unbiased system requires only one point at which the percentage of votes equals the percentage of seats: when each party receives $50 \%$ of the votes, the seats must be divided equally between them. The partisan fairness expressed by this symmetry does not restrict $x$ to equal $y$ at any but this point. When it is true that $x=y$, for all $x$ and $y$, we have the situation of unbiased proportional representation. However, there are many other interesting types of unbiased 


\section{Representation and Partisan Bias}

representation systems, and our model explicitly incorporates the full range of these. ${ }^{3}$

Bias, formalized as partisan asymmetry, makes it possible for one party to receive $50 \%$ of the votes but not necessarily $50 \%$ of the seats. This situation is modeled similarly: If $V=x \Rightarrow S=y$, then $V_{R}=x \Rightarrow S_{R}=z$, where $y$ is not necessarily equal to $z$. However, in the United States, even a biased system would not allocate any seats to a party without any votes. This means that both biased and unbiased systems are restricted to pass through the $(0 \%, 0 \%)$ and $(100 \%$, $100 \%$ ) points on the votes-to-seats curve; it is near the middle range of votes and seats that the potential for bias is greatest.

Our model of representation and bias will now be developed and explained in more detail. We introduce the mathematical form and explain the substantive significance of the bias and representation parameters of each. Those preferring a nonmathematical exposition are referred to Figures 1-3.

\section{Modeling Representation}

There are a number of plausible functional forms that could be used to model the full range of representation while still restricting the system to be unbiased. Most of these forms lead to nearly identical conclusions, if not to the same models. We believe our model best matches the definitions above and has the additional advantage of being a generalized form of the best-known model of the votes-seats relationship, the "cube law" of electoral politics. Our generalization also extracts the hidden features of this formal "law," known at least since 1909 (see Kendall and Stuart 1950), and expresses them in a more interpretable form. We show how this form can realistically and flexibly model concepts and relationships of fundamental importance to democratic theorists, political scientists, and the courts.
Equation 1, with $\rho$ set equal to 3 , is the classic cube law:

$$
\left(\frac{S}{1-S}\right)=\left(\frac{V}{1-V}\right)^{\rho}
$$

Some time after its inception, investigation with actual election results indicated that values for $\rho$ other than 3 were better descriptions of many electoral systems (see Taagepera 1973; Tufte 1973; and the citations in Grofman 1983, 317). While this mathematical relationship is straightforward, it is difficult to interpret in a theoretically meaningful way without either knowledge of analytical geometry or specific applications.

As an alternative, consider the algebraic characterization that follows. First, by taking natural logs, we rewrite Equation 1 as

$$
\ln \left(\frac{S}{1-S}\right)=\rho \ln \left(\frac{V}{1-V}\right)
$$

Tufte $(1973,545)$, making unrealistic assumptions about the disturbance term (see Linehan and Schrodt 1978), estimated $\rho$ by running a linear regression of $\ln [S /(1-S)]$ on $\ln [V /(1-V)]$ and including a constant term in the equation. ${ }^{4}$ With some additional algebraic manipulation, Equation 2 can be expressed as a modification of the dichotomous logit model (see King 1986a). Thus, from the perspective of models common in political science, Equation 3 should be more directly interpretable:

$s=D\left\{1+\exp \left[-\rho \ln \left(\frac{V}{1-V}\right)\right]\right\}_{(3)}^{-1}$

There are two differences between Equation 3 and the logit model commonly used to analyze dichotomous dependent variables: $\ln (V / 1-V)$ is a log-odds function of $V ;$ and there is no constant term. 


\section{American Political Science Review Vol. 81}

Figure 1. Forms of Unbiased Representation (Based on Equation 3)

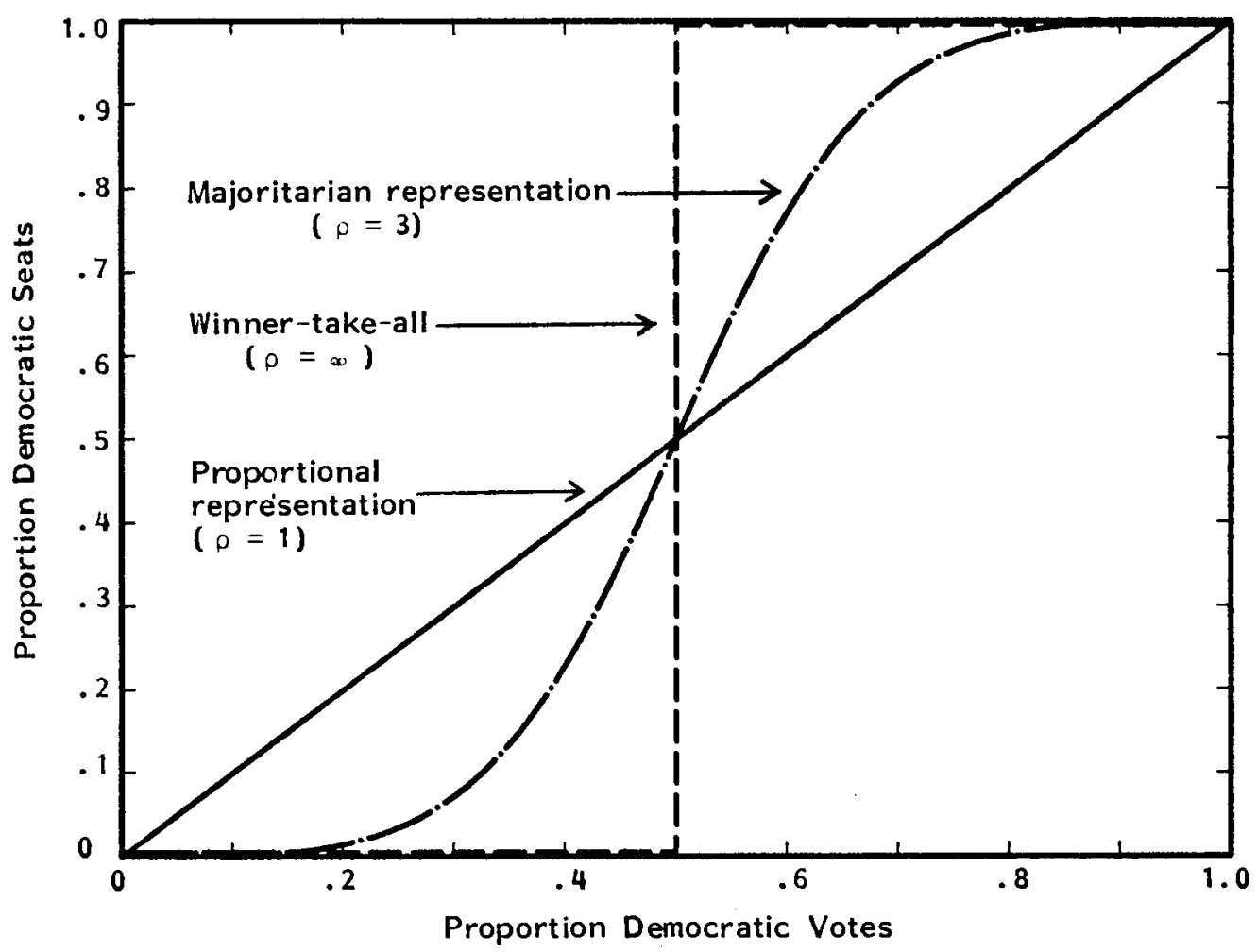

However, the inverse of the term in braces still ranges between 0 and 1 , and, when multiplied by $D$, the entire right-hand side is restricted to vary between 0 and $D$, the number of districts. Since a log-odds transformation is the inverse of a logit, we call Equation 3 the bilogit functional form. Thus, we have in Equation 3 a model that generates the forms of representation depicted in Figure 1.5

Figure 1 demonstrates the range of functional forms that can emerge from Equation 3 and depend on the value of $\rho$ (rhc), the representation parameter. We discuss winner-take-all representation ( $\rho$ $=\infty)$, majoritarian representation $(1<\rho$ $<\infty)$, and proportional representation
( $\rho=1$ ). Equation 3 can also be used to model antimajoritarian or unresponsive representation $(0<\rho<1)$, not discussed here.

When $\rho=1$, the translation of votes into seats is by proportional representation. As the figure indicates, some proportion of votes will yield exactly that proportion of seats for the Democratic party. Exact proportional representation is unlikely in actual U.S. district-based elections, if only because there are fewer seats than votes: it would require a proportional increase in seats $(1 / T$, to be precise) for even one additional vote; this is imp.ossible, unless there were one seat for each voter. Other more realistic condi- 


\section{Representation and Partisan Bias}

tions, such as incumbency and party competition, can also lead to results that are not proportional.

Majoritarian representation is the situation where $1<\rho<\infty$. The further $\rho$ is from 1 , the further the electoral system is from proportional representation. A common example of this is the cube law ( $\rho=$ 3 ), portrayed as the curve in Figure 1 in the shape of an escalator. This relationship between seats and votes helps majorities to form. When a party approaches $50 \%$ of the votes, each additional increment of voters increases the proportion of seats by a larger amount, as evidenced by the steep slope at $V=.5$ ); thus, parties are encouraged in their search for majorities. There is also an incentive for more partisan competition, since the marginal benefit, in terms of seats, of an additional increment of votes is greatest as both parties approach $50 \%$ of the votes. But one aspect of this relationship has been overlooked: although this form of representation favors majority and near-majority parties, there is a sense in which it protects minorities. This can be seen by looking near the top and bottom of the graph, where the slope of the line becomes progressively flatter. After a party gets 50\% of the vote (and a majority of seats), each additional increment of votes yields a smaller incremental proportion of seats. The increase in the proportion of majority-party voters it would take to eliminate the last percentage point of minority seats (i.e., from $99 \%$ to $100 \%$ for the majority party) is far greater than the increase in voters it would take to reduce minority representation by one percentage point near the middle of the curve (say, from $55 \%$ to $56 \%$ for the majority party). This majoritarian electoral system thus encourages majorities to form but simultaneously makes it more difficult for minority representation to be eliminated. Although only one type of majoritarian representation is pictured in Figure 1, there are an infinite number of possibilities-from just beyond proportional representation $(\rho>1)$ to just before winner-take-all $(r<\infty)$.

A third situation is winner-take-all, which occurs when $\rho=\infty$. This is also portrayed in Figure 1. In this case, 50\% plus one vote translates into $100 \%$ of the seats. Although this situation exists for each congressional district, for example, it does not usually apply to aggregates of them. ${ }^{\circ}$

Although proportional representation is most often proffered as the standard of fairness, we see no a priori reason to believe that one form of representation is inherently more fair than the others, provided that there is partisan symmetry. Convincing arguments can be made in favor of each of these types of democratic representation. At first glance proportional representation seems fair, since the translation process reflects underlying voter preferences most directly. But representation systems need not only reflect to be fair and meaningful (King and Ragsdale 1987; Pitkin 1967). Winner-take-all systems, for example, have some elements of reflection but also recognize that only one party can, and assume that only one party should, govern. These electoral systems thus emphasize ability to govern and reflection in the method of translating citizen votes into legislative seats. In general, there is a trade-off between these two criteria, but since winner-take-all systems do not favor one political party over the other, there is no real reason to consider it unfair. In fact, one can argue that majoritarian representation, falling between proportional and winner-take-all representation, best describes many popular notions of U.S. democracy: majorities are encouraged, but small minorities are protected and thus represented. An "optimal" value of $\rho$ is therefore a matter for political or judicial decision. Thus, there appears to be no a priori or axiomatic basis on which to choose one system over another.' 


\section{American Political Science Review Vol. 81}

\section{Modeling Bias}

Although there are many types of "fair" democratic systems of representation, partisan bias is usually condemned. Unfortunately, although partisan bias is often discussed, it is seldom estimated. Indeed, it is not even included as part of the cube law. In order to incorporate the possibility of bias into this model, we must choose a form that still restricts the votes-seats curve to pass through the $(0,0)$ and $(1,1)$ points; this means that a party with no votes will receive no seats. At the same time, this model must still allow for the full range of forms of representation already explicated.

Our solution is to augment Equation 1 (reinterpreted as Equation 3) with a bias parameter; this allows the joint estimation of both partisan bias and democratic representation. Letting $\beta$ (beta) be the bias parameter, the new generalized cube law can be written as ${ }^{8}$

$$
\left(\frac{S}{1-S}\right)=\beta\left(\frac{V}{1-V}\right)^{\rho}
$$

This form allows the curves drawn in Figure 1, from Equation 3, to be asymmetric, our definition of partisan bias. ${ }^{9}$

Almost every empirical study of the cube law has implicitly assumed that $\beta=$ 1 , the situation of no bias. When there is in fact no bias, the $\beta=1$ constraint causes no problem. However, when there is bias toward one of the political parties, the constraint will result in statistically inconsistent estimates. The model in Equation 4 allows for bias without the possibility of statistical inconsistency. Tufte (1973) was probably the first to recognize that bias and representation could be modeled in one equation, and his was a linear approximation to Equation 4. We believe our nonlinear model is a more realistic version than Tufte's in that we allow for every possible degree of partisan bias and every possible form of demo- cratic representation. Unlike the linear model, even systems with widely varying and quite extreme values of $S$ and $V$ can be incorporated in this model.

Equation 4 can also be written in an algebraically equivalent, but more substantively interpretable, bilogit form:

$$
\begin{gathered}
s=D\{1+\exp [-\ln (\beta) \\
\left.\left.-\rho \ln \left(\frac{V}{1-V}\right)\right]\right\}^{-1}
\end{gathered}
$$

We incorporate the bias parameter in this model because of widespread concern about the fairness of the congressional reapportionment process. We therefore provide a more realistic model of both bias and representation, allowing for the exact form of the bias to depend upon the specific type of electoral representation. Consider now what happens when bias is added to the unbiased forms of representation pictured in Figure 1.

Generically, bias refers to asymmetry in the seats-votes relationship for the two parties. The easiest type of bias to understand is for winner-take-all systems ( $\rho=$ $\infty)$. A bias in favor of the Republicans is the case where the discontinuity in the curve (the vertical part of the line in Fig. $1, \rho=\infty)$ is moved to the right: the proportion of the vote that the Democrats would have to win in order to take all the seats would be greater than half. Similarly, if the discontinuity moved to the left, the bias would help the Democrats. Bias in winner-take-all systems is so apparent that it rarely occurs in U.S. elections, except in the presence of fraud or other abuses. ${ }^{10}$ The particular forms of bias associated with the other two types of representation are quite distinct and more complex. The empirical results presented below indicate that bias coexists with many forms of representation in a number of U.S. states.

Table 1 summarizes the possible ranges 


\section{Representation and Partisan Bias}

of the bias parameter and their respective interpretations. Since $\beta$ is log-symmetric (ranging from 0 to $\infty$ with 1 at the center), it will be convenient to express the coefficient in terms of its natural $\log$, that is $\ln \beta$ (ranging from $-\infty$ to $\infty$ with 0 at the center).

Figure 2 plots three types of bias under a proportional representation system. ${ }^{11}$ $\ln \beta=0$ is obviously the case of no bias: .5 Democratic votes yields .5 Democratic seats; .6 Democratic votes yields .6 Democratic seats. This is proportional representation because the proportion of seats equals the proportion of votes; it is unbiased because these same figures also hold for the Republican party. The $45^{\circ}$
Table 1. Bias Coefficient Values

\begin{tabular}{ll}
\hline Coefficient Value & Direction of Bias \\
\hline $\ln \beta>0 \Leftrightarrow \beta>1$ & bias towards Democrats \\
$\ln \beta=0 \Leftrightarrow \beta=1$ & unbiased \\
$\ln \beta<0 \Leftrightarrow \beta<1$ & bias toward Republicans
\end{tabular}

line embodies this relationship; a given percentage change in seats yields an equal percentage change in votes throughout. In evaluating the other two biased lines, it is useful to consider this unbiased plot as the baseline.

For example, under proportional representation, .5 Democratic votes should

Figure 2. Bias and Proportional Representation (Based on Equation 5)

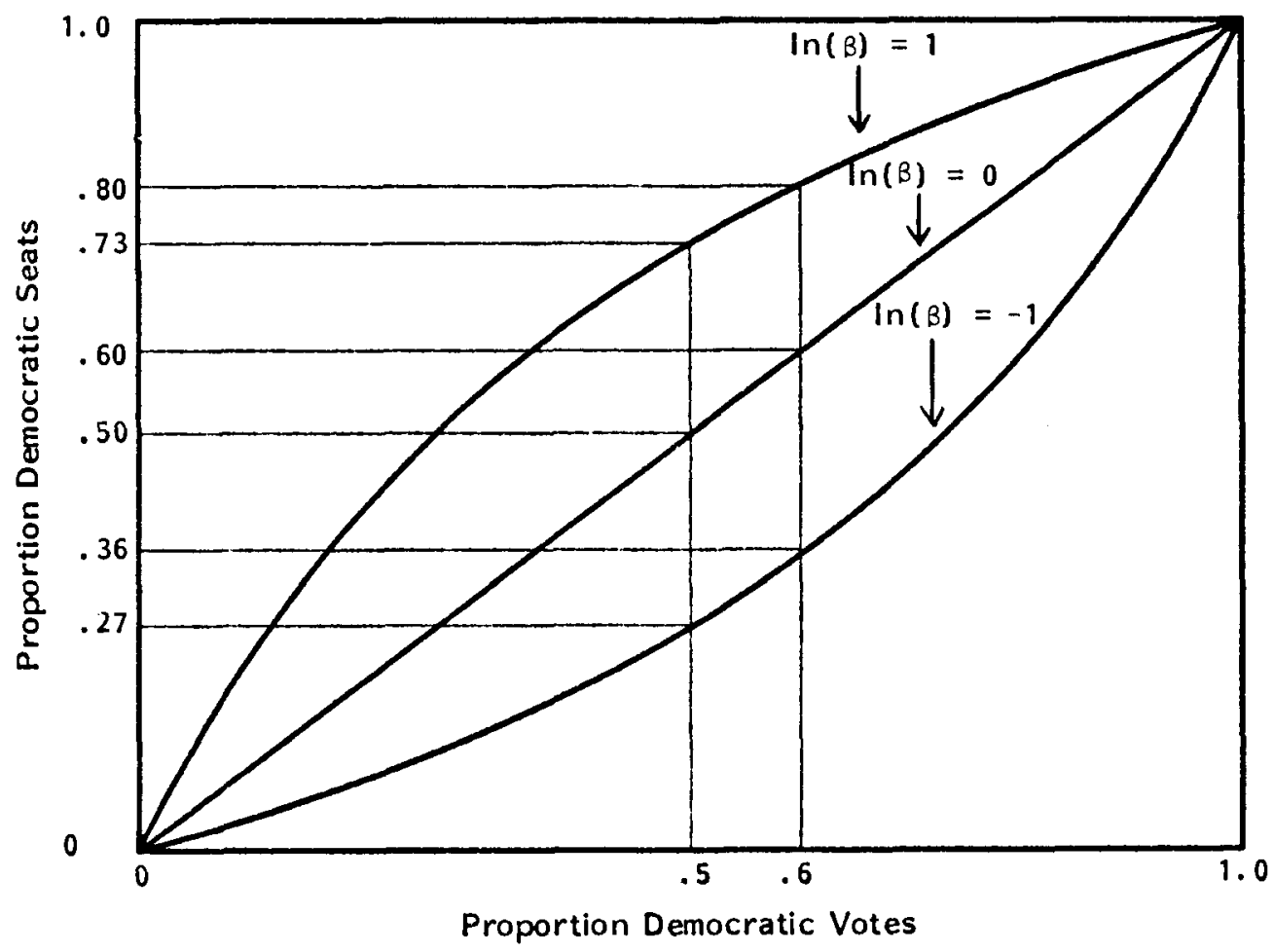




\section{American Political Science Review Vol. 81}

yield .5 Democratic seats (because this is where the vertical line meets the unbiased line), but the line marked $\ln \beta=-1$ only allocates .27 Democratic seats and the line marked $\ln \beta=1$ allocates .73. A similar situation exists at all other points on this graph. At .6 Democratic votes, the fair outcome is .6 Democratic seats, but the upper line, $\ln \beta=1$, is biased toward the Democrats, yielding .8 of the Democratic seats. The lower line, $\ln \beta=-1$, is biased toward the Republicans, yielding only .36 Democratic seats. The asymmetry defines our theoretical notion of bias.

Note that for each point on the horizontal axis, there is a different absolute bias for different parts of any biased line. For $\ln \beta=1$, the absolute bias is $|.5-.73|=$ .23 at .5 of the Democratic votes, but it is only $|.6-.8|=.20$ at .6 votes Democratic. In our model, the maximum absolute bias occurs at or near the .5 mark because the curves converge as they approach 0 or 1 . This provides some justification for formal statistical models (Quandt 1974) and more intuitive analyses (Tufte 1973) based on bias measured only at .5. However, since there are many electoral systems where the percentage Democratic is rarely near $50 \%$, it also suggests that we should look past this point to incorporate the full range of bias. For proportional representation systems, a measure based on the Gini index of the area between the biased and unbiased curves is possible, but this does not generalize as easily to the majoritarian representation or winner-take-all cases. Grofman's (1975, 1983) "normalized measure" of bias could be utilized here, but for present purposes the most natural way to measure the range of bias existing in the system is to use $\beta$ or, equivalently, $\ln \beta$.

Figure 3 expresses bias for majoritarian representation systems of the specific type $\rho=3$. The line in the middle, marked $\ln \beta$ $=0$, is the unbiased line included for reference. At 6 votes Democratic, the fair proportion of Democratic seats is .77.
This is fair under the $\rho=3$ majoritarian system, but not necessarily under other representational schemes. For the $\ln \beta=$ -1 line, there is a bias favoring the Republicans, so that the same .6 votes Democratic yields only a .55 proportion of Democratic seats. The $\ln \beta=1$ line, biased toward the Democrats, yields .9 of the Democratic seats. For this figure, the absolute bias is also different for each point on the horizontal axis. For the line marked $\ln \beta=1$, the absolute bias at .5 votes Democratic is $|.5-.73|=.23$, but the absolute bias at .6 is only $|.77-.90|$ $=.13 .{ }^{12}$

\section{Deterministic Laws and Probabilistic Realities}

Some of the most significant contributions to the literature on seats-votes relationships imply that the cube law, or some relevant variant, is deterministic. Whether this relationship is deterministic or probabilistic is an empirical issue, and it has important consequences for theoretical understanding and data analyses. We believe it is difficult to find even one mearingful example of a deterministic law anywhere in the social sciences. ${ }^{13}$ There is also strong evidence that a deterministic relationship between seats and votes does not exist: "While the cube law is stated deterministically, even a cursory examination of election statistics shows that it does not hold perfectly" (Schrodt 1981, 33). Michels's (1911) "Iron Law of Oligarchy" and many others have also failed the test. In making a general point (coincidentally using the cube law as an example), Achen (1982, 15) writes, "Any attempt at specifying exact causal functions must necessarily result in oversimplified explanations."

The Appendix develops a number of original, but somewhat technical, points: we justify a binomial disturbance term and add it to Equation 5, propose a 


\section{Representation and Partisan Bias}

Figure 3. Bias and Majoritarian Representation (Based on Equation 5; $\rho=3$ )

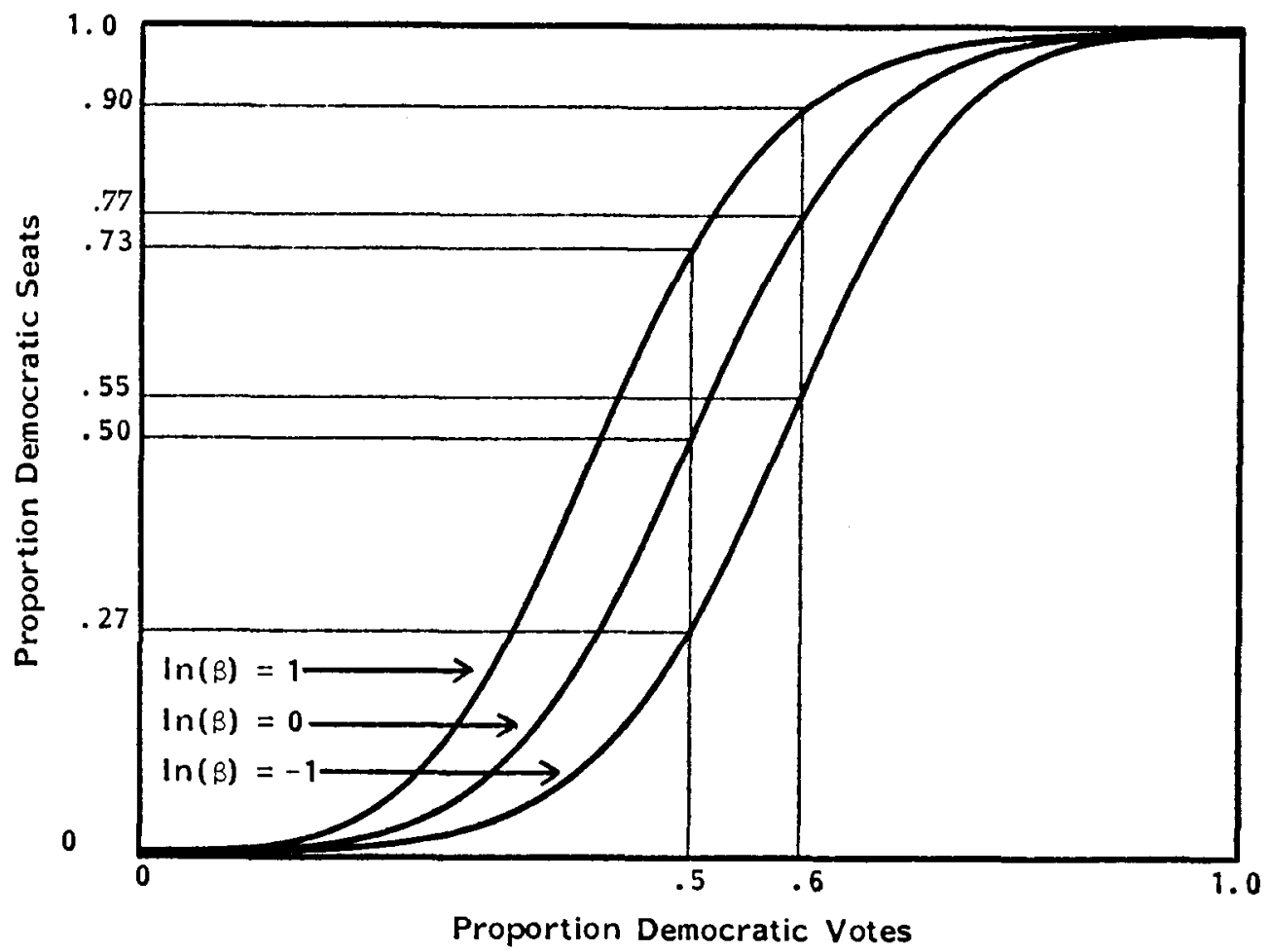

method of estimation, and provide some empirical estimates. The sections that follow use the results from the Appendix.

\section{Data and Measures}

To demonstrate the empirical utility of this model, it is applied to data on U.S. congressional elections, $1950-84 .^{14}$ For most analyses of the U.S. Congress, the entire nation has been used. But there are significant findings that demonstrate substantial variation across states (e.g., Scarrow 1983; Tufte 1973). We will therefore conduct separate analyses for each state, using the 18 elections between 1950 and 1984. Alaska and Hawaii were excluded because they were not states during the entire period. Small changes in the elections included in the analysis did not materially alter the results because of the generally slow changes in state electoral systems.

The implied assumption in this approach is that $\beta$ and $\rho$ vary more across states than over time within any one state. We believe that this is justifiable on two grounds. First, the whole process of reapportionment is conducted separately by each state legislature. Aside from significant variation in the decisions by state legislatures, there are also large discrepancies in political geography and political culture among the states. Surely, the 


\section{American Political Science Review Vol. 81}

variation over time would be less than these cross-state differences. Second, we report large variations in both the degree of bias and the type of representation across states (see Figs. 4 and 5). At the same time, empirical tests indicated substantial stability within states over time. ${ }^{15}$ If $\beta$ and $\rho$ do vary more than expected over time for a particular state, then our estimates are average values for that state.

These data were coded from, and crosschecked against, the Statistical Abstract of the U.S. (annual volumes), Congressional Quarterly's (1975) Guide to U.S. Elections, Cox's (1972) State and National Voting, 1910-1970, and Scammon and McGillivray's America Votes (annual volumes). As Niemi and Fett (1986) point out, the data collection is not as straightforward as it might seem. For example, we delete the very few representatives who had won seats under the independent-party label and subtracted the votes received by their Democratic and Republican opponents from the statewide total. We ignore resignations, deaths, and special elections. The member receiving the most votes in the general election was presumed to be elected. At-large districts, used by a few states immediately following reapportionment, are excluded unless there is only one district in the state. Several states have laws that do not require votes to be tabulated in uncontested races. For these states, we included only those districts and votes that were contested and reported. All other districts and votes are included.

Some have argued that the form of democratic representation is a function of the number of districts and voters, the geographical distribution, party competition, and the number of incumbents. Our approach follows two steps. We first estimate the bias and representation parameters for each state using the number of votes and seats for each party and election from 1950 to 1984 . Once these parameters have been estimated, we show how differ- ences in these estimates across states can be explained by measures of state political characteristics. This two-stage approach is as good as a simultaneous estimation because $\beta, \rho$, and many of these exogenous state characteristics change considerably more across states than over time. ${ }^{16}$

\section{Estimating Representation and Bias in U.S. House Elections}

Using Equation 5 as the general model, the estimation procedure described in the Appendix, and the data introduced below, bias and representation coefficients were estimated for each state. We present the results in Table A-1. For easier interpretation, Figure 4 presents a histogram of the representation coefficients. ${ }^{17}$ Note that the distribution of these coefficients are trimodal, with modes at or near 1,6 , and 10 . Most of the states are quite near to proportional representation, but significant numbers are strongly majoritarian, and several are approximately winner-take-all. Note that although $\rho$ ranges up to infinity, $\rho$ coefficients greater than 8 or 9 are essentially winnertake-all.

This finding demonstrates the utility of the model in three ways. First, it shows the large variance in the type of representation across states. Second, it demonstrates that the plurality of states are just above proportional representation $(\rho=$ 1). Although a number of studies have shown that $\rho$ is not equal to 3 , the cubelaw value, most find that $\rho$ falls between 2 and 4, with an average of about 3 . Finally, the results indicate that previous estimation procedures may have been statistically inconsistent due to the exclusion of a bias parameter. The extent of inconsistency in previous research is also quite substantial: although deriving an analytical expression for the inconsistency appears intractable, it is possible to get a feel for the extent of the problem. To 
Representation and Partisan Bias

Figure 4. Representation in U.S. States

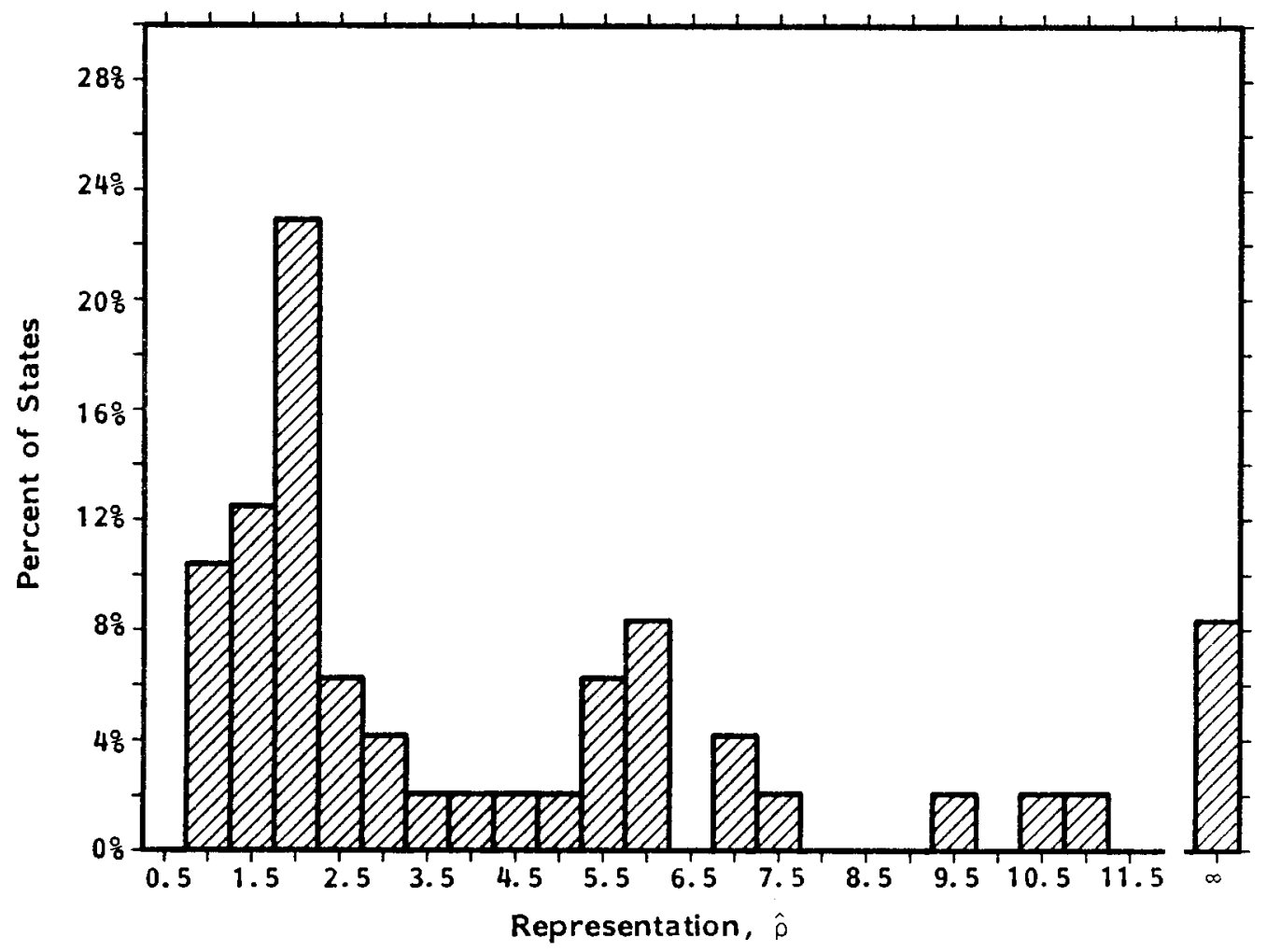

accomplish this, the state bilogit estimations were also run while constraining $\beta$ $=1$ [i.e., $\ln \beta=0$ ]-exactly as if the bias parameter had not been included. In these constrained estimations, $\rho$ was too large about 1.5 times more often than it was too small. It thus appears that previous research has overestimated the degree to which U.S. democracy tended away from proportional representation and toward majoritarian representation. Although these are the tendencies, in any particular example it is unclear whether the inconsistency will cause the estimate of $\rho$ to be too large or too small; the proper way to provide a consistent estimate of $\rho$ is to use the joint model and estimation method proposed here. ${ }^{18}$
There is also substantial variation in the degree and direction of bias in U.S. congressional elections across states. Figure 5 presents a histogram of the estimated $\beta$ coefficients. Note that the mean is almost exactly 0 , and there is an approximately symmetric normal distribution around this point. This implies that the average of the states is not too biased toward one party more than the other. However, not all points fall on or about $\ln \beta=0$, suggesting that at least some bias exists in individual states. In fact, even allowing for deviations from unbiasedness due to sampling variation and measurement error, the point estimates indicate that some states have quite large biases (see Fig. 5). There are two well-defined groups 


\section{American Political Science Review Vol. 81}

Figure 5. Bias in U.S. States

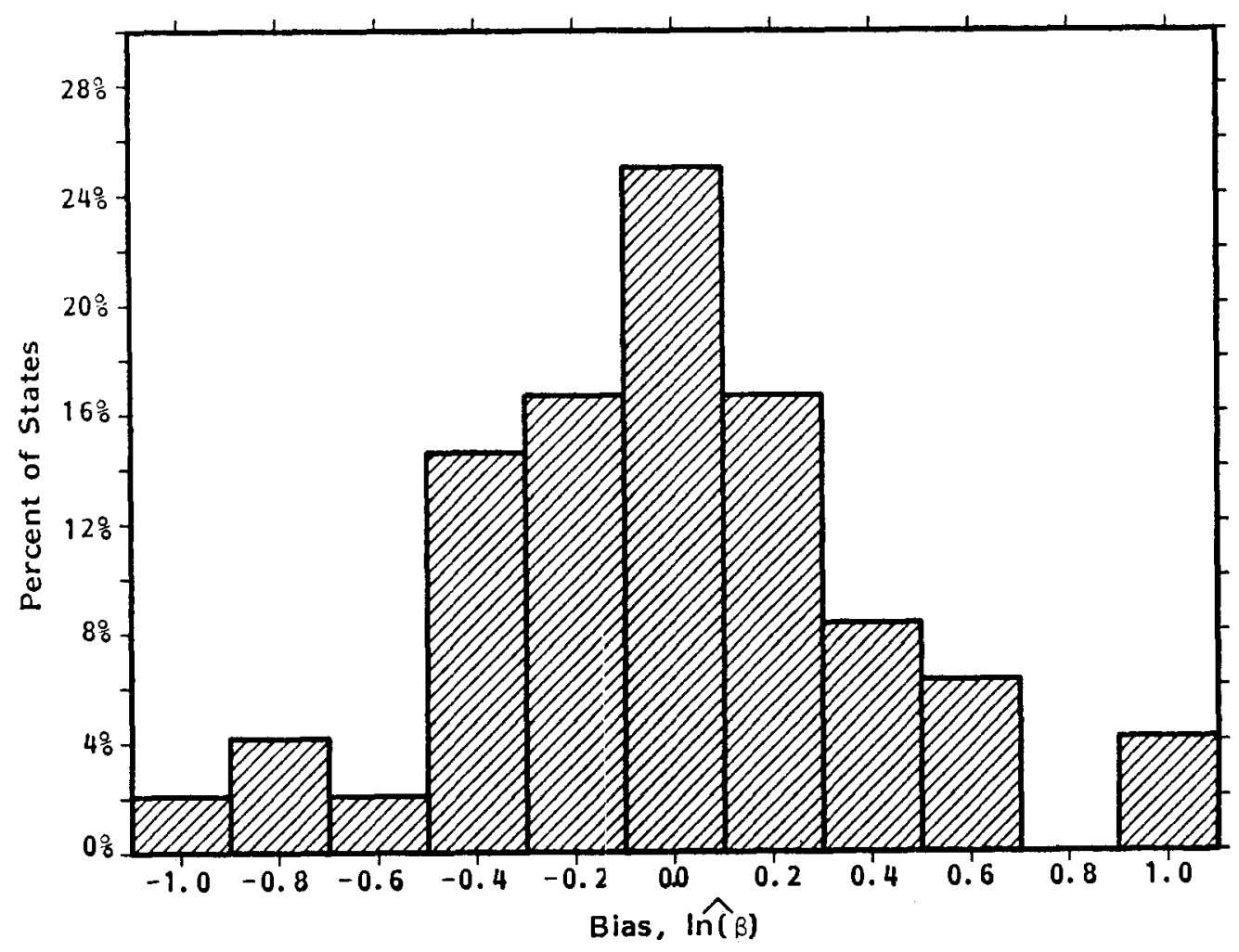

of outliers at the ends of Figure 5. Kansas, Michigan, and Ohio have a substantial Republican bias, whereas Texas, California, and Florida have a substantial Democratic bias. ${ }^{19}$

The effect of bias on proportional and majoritarian representation systems is seen in the examples of Indiana and Texas, graphed in Figures 6 and 7, respectively. Indiana is a generally Republican, but still competitive, two-party state. Our results indicate a very slight Republican bias (the unbiased baseline is almost indistinguishable from our empirical findings) and a steep, majoritarian, seats-votes relationship (the unbiased baseline is a steep curve with two sharp bends). Indiana and other strong party states tend to demonstrate the slight bias and steeper slope portrayed in this figure.

Representation in Texas is quite near to proportional. The no-bias baseline in Texas is the nearly straight-line proportional relationship (see Fig. 7). However, this baseline deviates substantially from Texas electoral politics; the dominant Democratic tradition has created quite severe biases toward the Democrats, permitting them to win a majority of the seats with less than $30 \%$ of the votes. This is an extreme example of the biases that do exist in U.S. politics. 
Representation and Partisan Bias

Figure 6. Bias and Representation in Indiana $(\hat{\rho}=5.70, \ln (\hat{\beta})=-.08)$

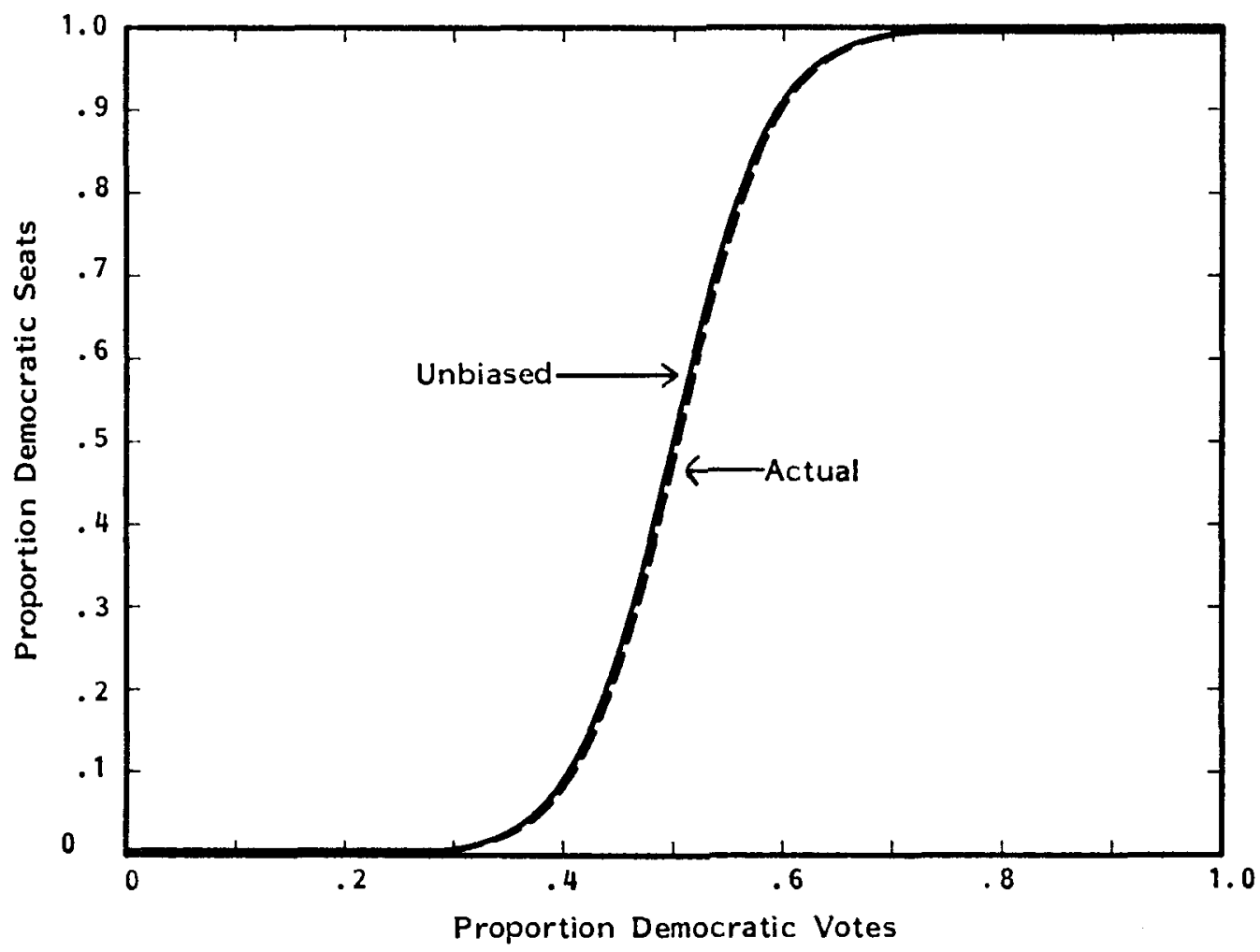

\section{Explaining Representation and Bias in the U.S. House}

In this section, we explore the differences among states in the bias and representation coefficients generated previously. This analysis helps to validate the estimates produced there. Leaving out the states with too little data for estimation or with coefficients equal to infinity (indicating winner-take-all representation), two series (bias and representation) of 44 observations each remain. The parameter estimates have different expected values (asymptotically equal to the population parameters) across states. The variation around these expected values is likely to be different for each coefficient, resulting in heteroscedastic disturbances. Fortu- nately, we can estimate these variances by the approximate squared standard error resulting from the first-stage analysis. Furthermore, since the first-stage analysis was estimated with maximum likelihood, these coefficients will be normally distributed.

Taking all these factors into account, we use a weighted least-squares analysis, regressing the estimates of representation and bias on separate sets of explanatory variables. ${ }^{20}$ Consider representation first. There are two main explanations for variation in the representation parameter. The best justified is Taagepera's (1973) index, $\ln (T) / \ln (D)$, where $T$ is the total number of voters and $D$ is the number of districts. To understand the logic behind this index, it is useful to focus on the 


\section{American Political Science Review Vol. 81}

Figure 7. Bias and Representation in Texas $(\hat{\rho}=1.05, \ln (\hat{\beta})=1.12)$

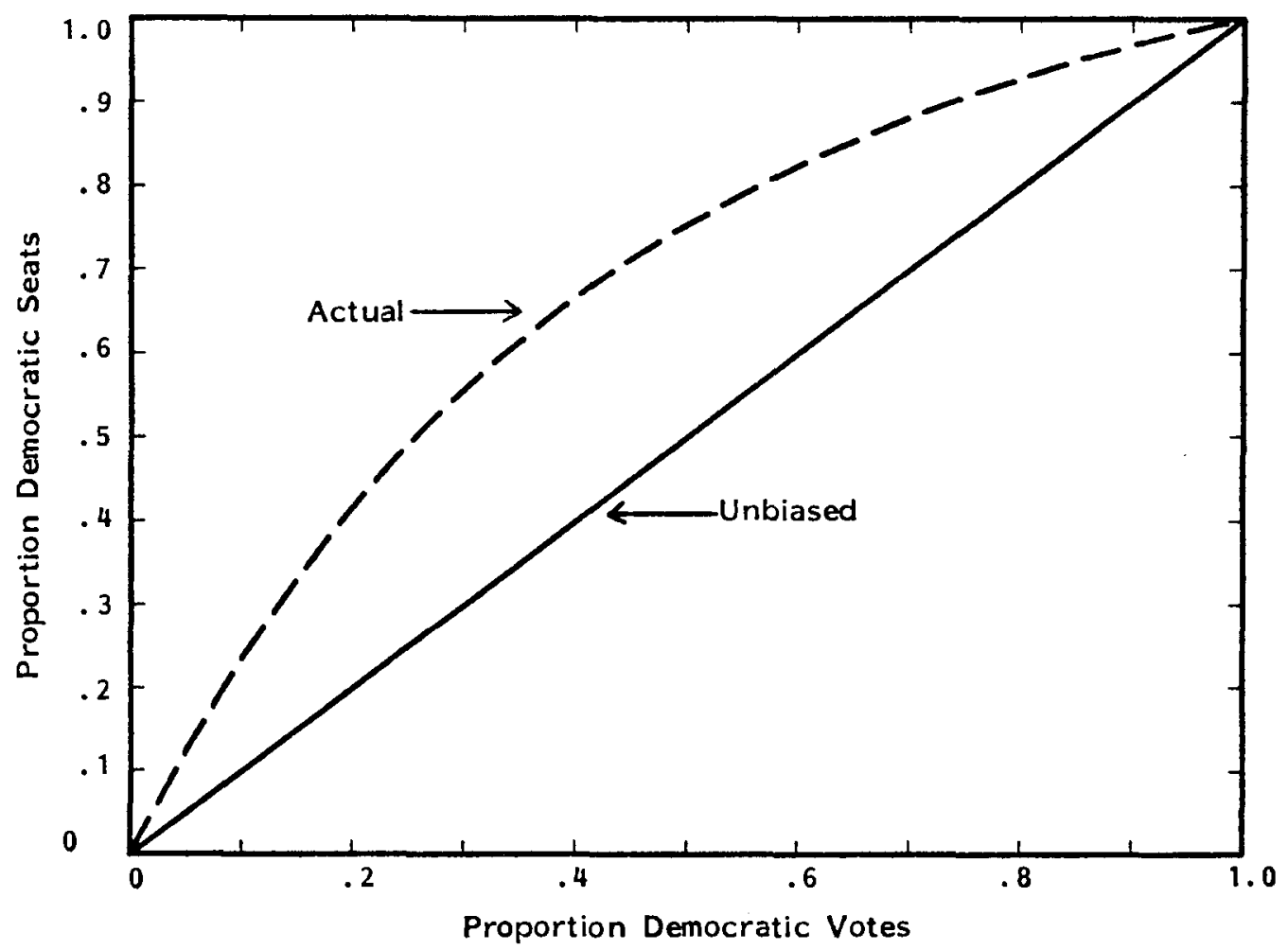

extreme cases. When there is no bias and one district for each voter (i.e., $T=D$ ), $x \%$ of the votes for one party will automatically yield $x \%$ of the seats for that party. This proportional representation result is captured by Taagepera's index, since $\ln (T) / \ln (D)$, where $T=D$, is equal to 1 . The winner-take-all extreme is also captured by this index: When there is only one district for all the voters, as in a presidential election, we have $\ln (T) / \ln (1)=$ $\ln (T) / 0 \approx \infty$. Thus, the extreme values of this index are theoretically appropriate. Between these two extremes, the index predicts a gradual and continuous increase in the representation parameterfrom proportional $(\rho=1)$ to majoritarian $(1<\rho<\infty)$ to winner-take-all $(\rho=\infty)$ forms of representation-as the number of districts increases relative to the number of voters. The precise rate at which $\rho$ increases is defined by the form of his index, $\ln (T) / \ln (D)$. Other forms that also meet the boundary conditions are possible, but Taagepera's (1973) seems plausible. In the weighted-least-squares regression analysis performed here, this hypothesis would be confirmed if the regression coefficient on this index were 1.0 and the coefficients on the other variables in the equation were 0 .

Party competition has been suggested as an examination for the form of representation. In strongly competitive party systems, where the percentage voting for each party in each election district is near $50 \%$, a small increase in votes for one party across districts will likely result in a 
Representation and Partisan Bias

Table 2. Explaining Representation

\begin{tabular}{lccc}
\hline \hline Independent Variable & Estimated Coefficient & Standard Error & $t$-Statistic \\
\hline Constant & -1.17 & .67 & - \\
Taagepera's index & .32 & .07 & 4.62 \\
Party competition & 2.17 & .70 & 3.09 \\
\hline
\end{tabular}

Note: Number of observations (states) $=44$; standard error of the weighted-least-squares regression $=.82$; mean of the dependent variable $(\hat{\rho})=1.54$.

large increase in seats for that party. Party competition also encompasses the effect of the power of incumbency and uncontested seats. From the widely used Ranney index of state party strength (Ranney 1976), we construct a measure of party competition that ranges from 0 (no competition) to 1 (pure competition). ${ }^{21}$

Table 2 presents the weighted leastsquares regression of our estimated representation parameters on Taagepera's index and party competition. The estimates for the effect of both variables are relatively precise and, at conventional levels, significantly different from 0 . Taagepera's index has an effect about onethird of what his theory would predict, but it has the correct sign, and helps to explain interstate variation in the form of representation. This finding has several interpretations: a different form of the index might account somewhat better for the range of representation types between proportional and winner-take-all, or there may be a tendency for U.S. states to be more proportional than would be expected solely on the basis of the relative sizes of their voter populations and numbers of legislative districts. Both the value of, and the need for further research on, Taagepera's index are emphasized by this result.

The effect of party competition is shown to be relatively strong: if a state were to move from the lowest to the highest level of partisan competition, the representation parameter would move more than two points toward the winner-takeall extreme (see Table 2). This is well within the bounds of the original hypothesis.

The propensity of a state to be biased toward the Republicans or Democrats has generally been explained by relative party strength. Parties may be in decline in some ways, but the desire to gerrymander remains as strong as ever. ${ }^{22}$ We would therefore expect all parties in all states to attempt to gerrymander, but only the states with dominant party systems would be successful.

As a measure of party strength, we use the Ranney index, ranging, as usual, from 0 (Republican) to 1 (Democratic). We also use a measure of state ideological orientation ranging from -1 (liberal) to 1 (conservative), estimated from state level CBS News-New York Times polls by Wright, Erikson, and McIver (1985).

The weighted-least-squares-regression results of estimated bias on state party strength and state ideological orientation are reported in Table 3 . Both coefficients are in the hypothesized directions, although the ideology coefficient does not meet conventional significance levels. Our results indicate that the strongest Democratic state has a bias coefficient about .9 points higher (in the direction of Democratic bias) than the strongest Republican state, and that ideologically liberal states tend to be somewhat more biased toward the Democrats.

The plausibility of these second-stage results lends criterion validity to our original model. Variations in our estimates of bias and representation in the U.S. states vary relatively closely with 


\section{American Political Science Review Vol. 81}

Table 3. Explaining Partisan Bias

\begin{tabular}{lccc}
\hline \hline Independent Variable & Estimated Coefficient & Standard Error & $t$-Statistic \\
\hline Constant & -.44 & .20 & - \\
Party strength & .90 & .32 & 2.82 \\
Ideology & -.67 & .59 & -1.15 \\
\hline
\end{tabular}

Note: Number of observations (states) $=44$; standard error of the weighted-least-squares regression $=.64$; mean of the dependent variable $(\hat{\rho})=-.05$.

these plausible criterion variables. Sensitivity analyses indicate that these findings are quire robust to marginally different specifications. $^{23}$

\section{Conclusion}

In this paper, the venerable cube law of electoral policies was reformulated, generalized, and reinterpreted to provide a model for the relationship between votes and seats in representative democracies. Whereas Taagepera (1986) generalized this law to proportional-representation elections, we generalize it to include both the form of democratic representation and the extent of partisan bias. Previous analyses tended to confuse the form of representation with the degree of partisan bias and have unintentionally constrained the partisan-bias parameter, in effect assuming no bias.

One consequence of this is that unbiasedness has mistakenly been associated with proportional representation. We find that all representation types captured by a single parameter in our model can treat the parties symmetrically using our definition of unbiasedness. Recent court rulings have upheld this view. ${ }^{24}$

Additionally, by constraining the $\beta$ parameter, past research has yielded statistically inconsistent estimates of the representation parameter, $\rho$, ranging between 2 and 4 for most electoral systems. In contrast, we find that the plurality of states were much closer to proportional representation than had been previously believed. Nevertheless, it is not true that all previous estimations of representation can simply be slightly adjusted toward 1.0. Although the empirical tendency is in this direction, the direction and size of the inconsistency is unknown for any particular example. Thus, some previous analyses may be overestimates and some may be underestimates. Statistical consistency requires that partisan bias be incorporated as an additional parameter. After all, if a party receives, for example, $55 \%$ of the votes and $75 \%$ of the seats, this may represent a severe partisan bias or a fair system with majoritarian representation. The only way to distinguish between the two situations is to have joint estimates of both $\beta$ and $\rho$.

The remarkably flexible bilogit functional form helped to highlight these problems with past research in the context of a theoretically meaningful solution. The model developed herein also demonstrates that different forms of representation are associated with different forms of bias, and that partisan bias can occur in widely varying degrees. This paper has also contributed to the statistical estimation of this inherently nondeterministic relationship between seats and votes. Applying a discrete probability distribution to the discrete variable, $s$, the number of Democratic seats, is a considerably more statistically efficient procedure than had previously been used. In an application to congressional elections, we demonstrate that there exists a wide variety of representation systems and degrees of 


\section{Representation and Partisan Bias}

partisan bias. These variations have important implications for national politics and policy (Browning 1986).

Finally, a second stage of the analysis provided some validity to the estimates from the first stage and some evidence that there are systematic explanations for the direction and size of the bias and representation parameters. The level of state party competition and Taagepera's index of state and electorate size helped to explain differences in the representation parameter estimates across states. The Ranney index of party strength and a measure of the state electorate's ideological orientations indicated when and where bias was more likely to occur.

Beyond these contributions, these results also have important implications for the recent court cases on reapportionment. First, the courts must explicitly distinguish between bias and representation type. The discussion of using seats and votes to create indicators of political discrimination in the federal-district-court decision in Bandemer $v$. Davis (603 F. Supp. 1479 [S.D. Ind. 1984]) reveals confusion on that court's part on this issue (see Browning and King n.d.). While it may be desirable for the courts to decide on an acceptable range for the type of representation in U.S. states, partisan bias is a separate issue. The courts would obviously prefer a system with no bias, but this too may not be possible. In such a case, the courts might establish an "acceptable" level of bias. Using this method numerous elections over at least a decade are necessary to make a confident determination about the degree of bias and type of representation. Perhaps in those states with a history of bias, the courts might more closely monitor the reapportionment process, or might even direct a court-ordered reapportionment plan. Regardless, this analysis can provide an understanding of the type of democratic representation and the existence of partisan bias over a historical series of elections for a particular state.

\section{Appendix}

We show how our emphasis on probabilistic relationships transforms Equation 5. We also resolve a problem existing in the political methodology literature so that $\beta$ and $\rho$ may be estimated efficiently and consistently. Estimates for each of the states appear in Table A-1.

Several authors have recently attempted to convert the deterministic cube law in Equation 1 (with $\rho=3$ ) to a statistical relationship. The main issue here is how to incorporate a disturbance term (Linehan and Schrodt 1978). ${ }^{25}$ Schrodt (1981) provides the most comprehensive analysis of possibilities but is ultimately unable to select any particular method: "In the absence of a theoretical justification for a specific error structure in the cube law, there is no a priori reason for choosing one . . . model over the others" (Schrodt 1981, 35-36).26

For a solution to this disturbance-term problem, we take a different approach. In reformulating the generalized cube law, we find that it is more politically interesting and more natural to model seats $(s)$ than the odds of seats $S /(1-S)$. The disturbance term should therefore be formulated in terms of the more fundamental and interpretable variable, $s$. Thus, we can rewrite Equation 5 to include an additive disturbance term:

$$
\begin{aligned}
& E(s)=D\{1+\exp [-\ln \beta \\
& \left.\left.\quad-\ln \left(\frac{V}{1-V}\right) \rho\right]\right\}^{-1} \\
& \text { or }=D\{1+\exp [-\ln \beta \\
& \left.\left.\quad-\rho \ln \left(\frac{V}{1-V}\right)\right]\right\}^{-1}+\epsilon
\end{aligned}
$$

The expected value operator, $E(\cdot)$, means that the functional form on the right hand side of Equation A-1 (a bilogit function of votes) will correctly predict the number of seats, $s$, on average over 


\section{American Political Science Review Vol. 81}

the long run. We assume in Equation A-2 that $E\left(\epsilon_{i}\right)=0$. This means that, over the long run, the average error is zero.

We now only need to choose a probability distribution for $s$ (or, equivalently, for $\epsilon$ ). Recall that $s$ is the number of seats allocated to the Democratic party. It is therefore a nonnegative integer ranging from 0 to $D$, the number of legislative districts. To incorporate as much information into the distribution as possible, we limit the range of possibilities to discrete probability distributions. The distribution should have the mean as a parameter but should not necessarily be symmetric, since the bounds at 0 and $D$ make symmetry either impossible or implausible for means not equal to $D / 2$. Instead, a formulation more faithful to the concept of partisan symmetry is required: the distributions with parameters $(D / 2)+\lambda$ and $(D / 2)-\lambda$ should be mirror images of one another. ${ }^{27}$

The binomial distribution meets each of these requirements and is relatively easy to work with. One possible problem is that district outcomes within a state may not be independent, as is assumed by the binomial distribution. Experiments with alternative formulations that allow dependence among districts were performed and were found to add little to the analyses below. This result is consistent with recent research indicating that congressional elections are local, not national, events, fought primarily within individual election districts (Hinckley 1981). The likelihood equation that emerges from this distribution and Equation 5 is also quite similar to what would result if a Poisson or a variety of other distributions were chosen (see King n.d., 1987); indeed, estimates from this model would be consistent even if the distribution were not binomial but were a member of the family of linear exponential distributions (Gourieroux, Monfort, and Trognon 1984). The results would therefore be quite similar if our assumption were incorrect.

Thus, for the analyses below, $s$ was assumed to be distributed binomially; that is,

$$
\begin{aligned}
& \operatorname{Pr}(s=k ; \theta \mid D)=[D ! /(D-k) ! k !] \\
& \quad(\theta / D)^{k}[1-(\theta / D)]^{D-k}
\end{aligned}
$$

where $\theta=E(s)$, from Equation A-1. $D$, the number of districts, is assumed to be known a priori. $\epsilon$ is defined as $\epsilon=s-\theta$. For a maximum likelihood solution, the log-likelihood equation, reduced to sufficient statistics, can be written by substituting Equation A-1 into Equation A-3, taking logs, simplifying, and summing over all observations:

$$
\begin{aligned}
& \ln \left(L_{i}\right)=\sum_{i=1}^{n}\left\{s _ { i } \left[\ln \left(D_{i}\right)\right.\right. \\
& \quad-\ln [1+\exp (-\ln \beta \\
& \left.\left.\left.-\ln \left(\frac{V}{1-V}\right) \rho\right)\right]\right] \\
& +\left(D_{i}-s_{i}\right) \ln [1-[1+\exp (-\ln \beta \\
& \left.\left.-\ln \left(\frac{V}{1-V}\right) \rho\{]^{-1}\right]\right\} \quad(\mathrm{A}-4)
\end{aligned}
$$

The Berndt et al. (1974) numericalestimation algorithm, in combination with the positive definite secant update method, was used to maximize this likelihood function to derive the estimates described in the next section. Relatively quick convergence was achieved in nearly all cases. ${ }^{28}$ The estimates of $\rho$ and $\beta$, along with standard errors for each, appear in Table A-1. This table is further discussed and analyzed in the text. 
Representation and Partisan Bias

Table A-1. Representation and Bias Coefficient Values

\begin{tabular}{|c|c|c|c|c|}
\hline States & $\hat{\rho}$ & $\begin{array}{c}\text { Standard } \\
\text { Error }\end{array}$ & $\ln (\hat{\beta})$ & $\begin{array}{c}\text { Standard } \\
\text { Error }\end{array}$ \\
\hline Alabama & 1.95 & 1.14 & -.70 & .93 \\
\hline Arizona & 1.55 & 1.78 & -.46 & .56 \\
\hline Arkansas & 1.95 & 1.10 & -.42 & 1.24 \\
\hline California & .93 & .57 & .16 & .09 \\
\hline Colorado & 2.08 & 2.55 & .39 & .51 \\
\hline Connecticut & 6.11 & 1.83 & .08 & .33 \\
\hline Delaware & $\infty$ & - & .00 & - \\
\hline Florida & 1.68 & .97 & .51 & .44 \\
\hline Georgia & 1.64 & 1.73 & .46 & 1.98 \\
\hline Idaho & 6.87 & 2.90 & .14 & .77 \\
\hline Illinois & 1.34 & 1.60 & -.09 & .25 \\
\hline Indiana & 5.70 & 2.39 & -.08 & .32 \\
\hline Iowa & 7.07 & 2.13 & -.31 & .41 \\
\hline Kansas & 2.43 & 1.68 & -.82 & .60 \\
\hline Kentucky & 1.16 & 1.95 & .51 & .67 \\
\hline Louisiana & 2.11 & 1.40 & .04 & 1.81 \\
\hline Maine & 11.87 & 7.65 & -.92 & 1.50 \\
\hline Maryland & 2.35 & 1.96 & .02 & .94 \\
\hline Massachusetts & 1.96 & 1.04 & -.14 & .57 \\
\hline Michigan & 3.23 & 1.96 & -.47 & .32 \\
\hline Minnesota & 1.97 & 4.62 & -.17 & .51 \\
\hline Mississippi & 1.38 & .92 & -.04 & 1.48 \\
\hline Missouri & 2.62 & 2.62 & .59 & .80 \\
\hline Montana & 2.11 & 4.17 & .14 & 1.38 \\
\hline Nebraska & 3.98 & 2.38 & -.82 & .93 \\
\hline Nevada & $1 \infty$ & - & .00 & $\ddot{-}$ \\
\hline New Hampshire & 6.31 & 5.48 & -.13 & 1.37 \\
\hline New Jersey & 2.83 & 2.37 & .11 & .25 \\
\hline New Mexico & 5.15 & 2.34 & .25 & .44 \\
\hline New York & 2.06 & .98 & .06 & .14 \\
\hline North Carolina & $\infty$ & - & .00 & - \\
\hline North Dakota & 7.43 & 7.88 & -.25 & 2.20 \\
\hline Ohio & 2.04 & 1.65 & -.37 & .28 \\
\hline Oklahoma & 1.17 & 5.02 & .95 & 1.58 \\
\hline Oregon & 4.74 & 2.17 & -.25 & .55 \\
\hline Pennsylvania & 1.63 & 1.25 & -.03 & .17 \\
\hline Rhode Island & 11.23 & 19.11 & -.33 & 3.59 \\
\hline South Carolina & 2.20 & 1.66 & -.12 & .75 \\
\hline South Dakota & 9.72 & 6.61 & -.30 & .94 \\
\hline Tennessee & 1.25 & 1.62 & .18 & .66 \\
\hline Texas & 1.05 & .79 & 1.12 & .68 \\
\hline Utah & 10.60 & 4.43 & .25 & .67 \\
\hline Vermont & $\infty$ & - & .00 & - \\
\hline Virginia & 2.09 & 1.54 & -.21 & .32 \\
\hline Washington & 5.39 & 1.11 & -.06 & .25 \\
\hline West Virginia & 5.67 & 5.06 & .26 & 1.57 \\
\hline Wisconsin & 3.52 & 1.88 & -.32 & .37 \\
\hline Wyoming & $\infty$ & - & .00 & - \\
\hline
\end{tabular}




\section{American Political Science Review Vol. 81}

\section{Notes}

We appreciate the comments on earlier drafts of this work by, and discussions with, Christopher Achen, Nathaniel Beck, Gerald Benjamin, Paul Brace, Steven Brams, William Browning, Bernard Grofman, Seung-Hyun Kim, William McLauchlan, Elizabeth Rosenthal, and William Shaffer. Hsing-Pei Gary Kao and Seung-Hyun Kim assisted with the data collection.

1. The "swing ratio" is related to what we call representation. However, the swing ratio-the slope of an estimated linear relationship between seats and votes - is too restrictive to model the full range of nonlinear representational forms.

2. Because most nondemocratic regimes also have voting, the seats-votes relationship is important there as well. However, the mechanism for translation is obviously very different.

3. In Davis v. Bandemer (p. 2809), the Supreme Court recognized that previous cases "clearly foreclose any claim that the Constitution requires proportional representation or that legislatures in reapportioning must draw district lines as near as possible to allocating seats to the contending parties in proportion to what their anticipated statewide vote will be."

4. For most of his analyses, Tufte (1973) used a linear approximation to this form because at the time the logistic form was less commonly used and because the lack of extreme points in his data made the approximation relatively good. Since 1973 , the logistic model has been considerably more popular; the figures in this paper will also aid in this interpretation. In addition, the data used in the bias section, as well as the data available from other electoral systems, have substantial numbers of extreme data points. Finally, as the figures will show, a linear approximation is not reasonable for many interesting and empirically common forms of bias and representation.

5. The bilogit form is formally undefined when $\rho=\infty$. As a result, it would be technically more appropriate to characterize the winner-take-all situation as $\rho \rightarrow \infty$.

6 . Theil $(1969,521)$ describes a real electoral situation where the system was created to help the minority at the expense of the majority. Although this antimajoritarian representation system is unJikely to occur much in U.S. politics, it can be represented in the current scheme as $\rho<1$.

7. In an interesting but wholly impractical proposal, Theil $(1969,524)$ suggests that citizens express a preference for $\rho$ at the same time as they vote for candidates. Preferences for $\rho$ would then be aggregated before translating votes into seats. Although it is not reasonable to "require the teaching of logarithms at an early stage" $(1969,524)$, this proposal does suggest the importance of the $\rho$ coefficient in standing for the type of representation in the electoral system.

8. If we used $V_{R}$ and $S_{R}$ in place of $V$ and $S$, respectively, then the bias parameter would be $\beta_{R}=$ $1 / \beta$. Thus, $\beta$ is implicitly defined in terms of Democrats.

9. In systems where each party is guaranteed some minimum number of seats regardless of the outcome of the vote, it would be possible to include an additive parameter in Equation 4 to take this into account. However, for congressional elections, this is obviously not relevant.

10. This type of bias occurs, for example, in decisions of legislatures to seat members following closely contested elections. Since the majority party in the legislature can establish its own rules to count disputed ballots, the member seated may not be the candidate with the most votes. In our data, we assume that the candidate with the most votes wins the seat and ignore the bias that occurs if the legislature sat the "loser."

11. These values for $\beta$ are empirically reasonable in the context of the analysis presented below.

12. Note that this demonstrates that a Gini index measure is inappropriate unless proportional representation is deemed the only fair representation system. If some form of majoritarian representation were considered acceptable, then comparing one of the biased curves in Figure 3 to be the fair proportionality curve in Figure 2 will be misleading; indeed, by that standard, even the fair majoritarian curve would be considered biased. It might be useful to generalize the Gini index and derive a measure of bias based on the area between the unbiased $(\beta=0$ and $\rho$ unconstrained) and the actual bias ( $\beta$ and $\rho$ unconstrained) curves, thus incorporating all the absolute biases. But this is not needed, since $\ln \beta$ contains all of this information.

13. Indeed, many modern-day physicists do not believe that even the physical world is deterministic (see the discussion in Zellner 1984).

14. Niemi and Fett (1986) review several possibilities and conclude that their "historical swing ratio" is better than their "biyearly form." The main reason is that many data points are better than two. Curiously, Kowever, they conclude their article by favoring the "hypothetical (single-year) swing ratio." They give other reasons for preferring this method, but we do not conclude as they do that many data points are better than two, but that one datum is better than many. Our analysis will therefore use many data points collected over time.

15. The data were split into two nine-electionyear samples for each state. The two sets each of $\beta$ and $\rho$ coefficients were each then correlated. Since positive infinity is a possible value for $\rho$, a simple measure of association was not possible. Omitting these values usually led to correlation coefficients of about .45. More revealing were scatterplots that indicated closer fits between the two time periods 


\section{Representation and Partisan Bias}

than any single coefficient could demonstrate. We also split the data to test whether the "one man, one vote" Supreme Court decision had an effect on $\rho$ and $\beta$. As one would expect, we concluded that changes in state politics occur slowly. Incumbency, political parties, and geographical and constitutional factors prevent wholesale changes in the structure of representation and bias.

16. One might hypothesize that $\rho$ is a linear function of a vector of explanatory variables, such as state size $\left(X_{1}\right)$ and party competition $\left(X_{2}\right): \rho=\alpha_{1}+$ $\alpha_{1} X_{1}+\alpha_{2}+X_{2}$. It might also be reasonable to hypothesize that $\beta$ is a function of explanatory variables such as party strength $\left(Z_{1}\right)$ and state ideological orientation $\left(Z_{2}\right): \beta=\gamma_{0}+\gamma_{1} Z_{1}+\gamma_{2} Z_{2}$. The right hand side of these two equations could then be substituted into Equation 5 to derive reduced-form estimates-resulting in a form analogous to interaction effects in regression analysis. This procedure is inapplicable here, however, because $\beta$ and $\rho$ are assumed to vary only across states. An alternative procedure is used below to express $\hat{\rho}$ and $\hat{\beta}$ as stochastic functions of these explanatory variables.

17. As is apparent from Equation 5, no estimates can be computed when a party received 0 votes for a year or when there is no variation in the number of seats across the years. For this reason, the coefficients of several of the states were not calculated on the full 18 years. The estimates from the following states are therefore not as reliable, since they have one or more years omitted (noted in parentheses): Georgia (1950, 1952, 1958), Louisiana (1950), Missouri $(1954,1956,1958,1962)$, South Carolina (1950, 1958, 1960), and Arkansas (1950, 1954, 1958). This and other causes of imprecision in the estimates are indicated in the standard errors in Table A-1.

18. It is likely that (1) less biased states (i.e., with smaller absolute values of $\ln \beta$ ) and (2) states where bias and representation vary independently will be closer to consistency than others, but there is no consistent way to know this or to estimate the bias parameter without the full joint estimation presented here.

19. The negative signs indicate bias toward the Republicans; the positive coefficients indicate Democratic bias. Most of the states listed in Table A-1 have estimated $\rho$ and $\beta$ coefficients within range of what one would expect. The exceptions are mostly those with large standard errors. These substantive points are more directly analyzed in the U.S. House.

20. The residuals from the two regressions correlated at only -.117 ( $t$-value $=-.765$ ). A seemingly unrelated regression would therefore be of no help here.

21. If we let $R$ stand for the raw Ranney index, the measure described as party competition in the text is calculated as $1-2|R-.5|$. This is the distance from being in between the parties, normalized to a $0-1$ scale.

22. For example, the architect of the recent and controversial California redistricting plan, late Congressman Phillip Burton (D-San Francisco), "did not deny that the gerrymander was alive and well in California. Burton publicly joked that his zigzagging district lines were "our contribution to modern art' " (Lowell and Craigie 1985, 246).

23. In particular, no evidence of regional effects could be found: after controlling for the other variables in the equations, the South and other regions were not more likely to be characterized by different levels of bias or representation. There was also no interactive regional effect on the coefficients from the weighted-least-squares results.

24. The plurality in Davis v. Bandemer (n. 9) recognized that there was a range of fair seats-votes relationships that are not proportional. Justices White, Brennan, Marshall, and Blackmun's comment that their opinion "is not a preference for proportionality per se but a preference for a level of parity between votes and representation sufficient to ensure that significant minority voices are heard and that majorities are not consigned to minority status is hardly an illegitimate extrapolation from our general majoritarian ethic and the objective of fair and adequate representation recognized in Reynolds v. Sims."

25. It is useful to express relationships statistically even if there is no explicit sampling procedure. One only need conceptualize the dependent variable (Democratic seats, in this case) as a function of systematic (votes Democratic in the bilogit form) and random factors. The random factors are represented by a disturbance term with some known probability distribution.

26. Schrodt finds that three of the five models "have the undesirable property of varying depending on which party is in the numerator and denominator" $(1981,36)$. (Our model avoids this problem: $\rho$ is invariant and only the sign of $\ln \beta$ changes by using the Republican, instead of Democratic, party for $V$.) Of the remaining two, he concludes after empirical analyses that one "appears to have little utility" (p. 41). The final model seems best, but it produces the largest standard errors in applications. It also assumes that the disturbance term is lognormal, which may be appropriate at times, but "is not the sort of probability distribution for an error term that one is likely to choose by default" (Linehan and Schrodt 1978).

27. Most probability distributions are eliminated by these axioms. The Poisson distribution is not bounded from above (King n.d.), and the truncated Poisson distribution does not meet the invariant requirement (Johnson and Kotz 1969). The betabinomial and contagious binomial distributions are possibilities, but the latter makes implausible assumptions about sequential influence structures among congressional districts and the former is elim- 


\section{American Political Science Review Vol. 81}

inated on empirical grounds.

28. We estimate $\ln \beta$ instead of $\beta$ because it is more easily interpreted. Furthermore, because of the invariance property of maximum-likelihood estimation (DeGroot 1975, 291-92), the exponentiation of the estimate of $\ln \beta$ may be calculated in order to recover the maximum likelihood estimate of $\beta$.

\section{References}

Achen, Christopher. 1982. Interpreting and Using Regression Analysis. Beverly Hills: Sage.

Balinski, Michel L., and H. Peyton Young. 1982. Fair Representation. New Haven: Yale University Press.

Berndt, E. K., B. H. Hall, R. E. Hall, and J. A. Hausman. 1974. Estimation and Inference in Nonlinear Structural Models. Annals of Economic and Social Measurement 3:653-65.

Browning, Robert X. 1986. Politics and Social Welfare Policy in the United States. Knoxville: University of Tennessee Press.

Browning, Robert $X$, and Gary King. N.d. Seats, Votes, and Gerrymandering: Estimating Representation and Bias in State Legislative Redistricting. Law and Policy. Forthcoming.

Cain, Bruce. 1984. The Reapportionment Puzzle. Berkeley: University of California Press.

Congressional Quarterly. 1975. Guide to U.S. Elections. Washington: author.

Cox, Edward F. 1972. State and National Voting, 1910-1970. Hamdon, CT: Archon.

Dahl, Robert A. 1956. A Preface to Democratic Theory. Chicago: University of Chicago Press.

DeGroot, Morris H. 1975. Probability and Statistics. Menlo Park, CA: Addison-Wesley.

Farrand, Max. 1911. The Records of the Federal Convention of 1787. New Haven: Yale University Press.

Gourieroux, C., A. Monfort, and A. Trognon. 1984. Pseudo Maximum Likelihood Methods: Theory. Econometrica 52:681-700.

Grofman, Bernard N. 1975. A Review of MacroElection Systems. Political Yearbook 4:303-52.

Grofman, Bernard N. 1983. Measures of Bias and Proportionality in Seats-Votes Relationships. Political Methodology 9:295-327.

Grofman, Bernard N., Arend Lijphart, Robert B. McKay, and Howard A. Scarrow. 1982. Representation and Redistricting Issues. Lexington, MA: D. C. Heath.

Hay and Rumley. 1984. On Testing for Structural Effects in Electoral Geography, Using Entropy-maximizing Methods for Estimate Voting Patterns. Environment and Planning: $A$ 16:233-40.

Hinckley, Barbara. 1981. Congressional Elections. Washington: Congressional Quarterly.

Johnson, Norman L., and Samuel Kotz. 1969.
Discrete Distributions. New York: Wiley.

Kendall, M. G., and A. Stuart. 1950. The Law of Cubic Proportion in Election Results. British Journal of Sociology 1:183-97.

King, Gary. 1986a. How Not to Lie with Statistics: Avoiding Common Mistakes in Quantitative Political Science. American Joumal of Political Science 30(3):666-87.

King, Gary. N.d. Statistical Models for Political Science Event Counts: Bias in Conventional Procedures and Evidence for the Exponential Poisson Regression Model. American Joumal of Political Science. Forthcoming.

King, Gary. 1987. Variance Specification in Event Count Models: From Restrictive Assumptions to a Generalized Estimator. Paper presented at the annual meeting of the Political Science Methodology Group, Durham, NC.

King, Gary, and Lyn Ragsdale. 1987. The Elusive Executive: Discovering Statistical Patterns in the Presidency. Washington: Congressional. Quarterly.

Linehan, William J., and Phillip A. Schrodt. 1978. A New Test of the Cube Law. Political Methodology 4:353-67.

Locke, John. 1965. Two Treatises of Government. New York: New American Library.

Lowell, Frederick K., and Teresa A. Craigie. 1985. California's Reapportionment Struggle: A Classic Clash between Law and Politics. Journal of Law and Politics 2:245-62.

March, James G. 1957/58. Party Legislative Elections as a Function of Election Results. Public Opinion Quarterly 11:521-42.

Michels, Robert. 1911. Political Parties. New York: Free Press.

Niemi, Richard G., and Patrick Fett. 1986. The Swing Ratio: An Explanation and an Assessment. Legislative Studies Quarterly 11(1):75-90.

Pitkin, Hanna. 1967. The Concept of Representation. Berkeley: University of California Press.

Polsby, Nelson W. 1971. Reapportionment in the 1970s. Berkeley: University of California Press.

Quandt, Richard E. 1974. A Stochastic Model of Elections in Two-Party Systems. Joumal of the American Statistical Association 69(346):315-24.

Rae, Douglas. 1967. The Political Consequences of Electoral Laws. New Haven: Yale University Press.

Ranney, Austin. 1976. Parties in State Politics. In Politics in the American States: $A$ Comparative Analysis, 3 d ed., ed. Herbert Jacob and Kenneth N. Vines. Boston: Little, Brown.

Scammon, Richard, and A. V. McGillivray. Annual volumes 1950-84. America Votes. Congressional Quarterly.

Scarrow, Howard A. 1983. Parties, Elections, and Representation in the State of New York. New York: New York University Press.

Schattschneider, Elmer E. 1942. The Semi-sovereign 


\section{Representation and Partisan Bias}

People. New York: Holt, Rinehart \& Winston.

Schrodt, Philip A. 1981. A Statistical Study of the

Cube Law in Five Electoral Systems. Political Methodology 7:31-53.

Taagepera, Rein. 1973. Seats and Votes: A Generalization of the Cube Law of Elections. Social Science Research 2:257-75.

Taagepera, Rein. 1986. Reformulating the Cube Law for Proportional Representation Elections. American Political Science Review 80:489-504.

Theil, Henri. 1969. The Desired Political Entropy. American Political Science Review 63:521-25.

Theil, Henri. 1970. The Cube Law Revisited. Joumal of the American Statistical Association
65:1213-19.

Tufte, Edward R. 1973. The Relationship between Seats and Votes in Two-Party Systems. American Political Science Review 67:540-54.

United States Department of Commerce, Bureau of Census. Annual volumes 1950-1984. Statistical Abstract of the U.S. Washington: GPO.

Wright, Gerald C., Jr., Robert S. Erikson, and John P. McIver. 1985. Measuring State Partisanship and Ideology with Survey Data. Joumal of Politics 47:469-89.

Zellner, Arnold. 1984. Basic Issues in Econometrics. Chicago: University of Chicago Press.

Gary King is Associate Professor of Government, Harvard University, Cambridge, MA 02138 .

Robert X Browning is Associate Professor of Political Science, Purdue University, West Lafayette, IN 47907. 